\title{
Simple Analytical Expressions for the Force and Torque of Axial Magnetic Couplings
}

\author{
Thierry Lubin, Smail Mezani, and Abderrezak Rezzoug
}

\begin{abstract}
In this paper, a theoretical analysis of an axial magnetic coupling is presented, leading to new closed-form expressions for the magnetic axial-force and torque. These expressions are obtained by using a two-dimensional (2-D) approximation of the magnetic coupling geometry (mean radius model). The analytical method is based on the solution of Laplace's and Poisson's equations by the separation of variables method. The influence of geometrical parameters such as number of pole pairs and air-gap length is studied. Magnetic field distribution, axial force and torque computed with the proposed 2-D analytical model are compared with those obtained from 3-D finite elements simulations and experimental results.
\end{abstract}

Index Terms - Torque transmission, axial magnetic coupling, analytical model, axial force.

\section{INTRODUCTION}

$\mathrm{M}$ AGNETIC couplings are of great interest in many industrial applications. They can transmit a torque from a primary driver to a follower without mechanical contact. As the torque could be transmitted across a separation wall, axial field magnetic couplings are well suited for use in isolated systems such as vacuum or high pressure vessels. Moreover, they present a maximum transmissible torque (pull-out torque) giving an intrinsic overload protection.

Axial magnetic couplings consist of two opposing discs equipped with rare earth permanent magnets as shown in Fig. 1. The magnets are magnetized in the axial direction. They are arranged to obtain alternately north and south poles. The flux is closed by soft-iron yokes. The torque applied to one disc is transferred through an air-gap to the other disc. The angular shift between the two discs depends on the transmitted torque value. The main drawback of axial-type magnetic couplings is the significant value of the axial attractive force between the two discs.

An accurate knowledge of the magnetic field distribution is necessary for predicting the torque and the axial force. The magnetic field can be evaluated by analytical methods [1-22] or by numerical techniques like finite elements [23-26].

Finite elements simulations give accurate results considering three dimensional (3-D) effects and nonlinearity of magnetic materials. However, this method is computer time consuming

Manuscript received October 31, 2011

T. Lubin, S. Mezani and A. Rezzoug are with the Groupe de Recherche en Electrotechnique et Electronique de Nancy (GREEN), Université Henri Poincaré, 54506 Nancy, France (e-mail: thierry.lubin@green.uhp-nancy.fr).

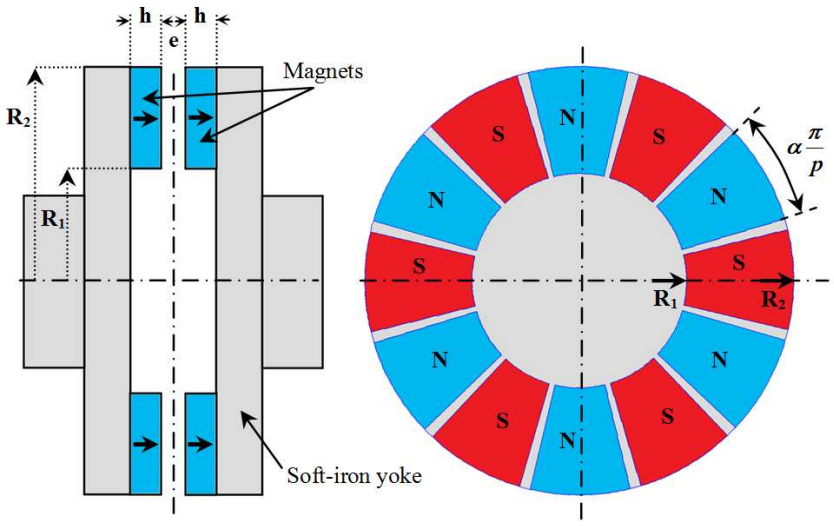

Fig. 1. Geometry of the studied axial-type magnetic coupling $(p=6)$

and poorly flexible for the first step of design stage.

Analytical methods are, in general, less computational time consuming than numerical ones and can provide closed-form solutions giving physical insight for designers. So, they are useful tools for first evaluations of magnetic couplings performances and for the first step of design optimization.

Three-dimensional analytical models for ironless permanent magnet couplings have been proposed in the literature [1-16]. The proposed models are developed for axial magnetic couplings with parallelepiped magnets or cylindrical tile magnets. As the magnets are in free space (with no other magnetic materials present), analysis is based either on the amperian model with Biot-Savart law or on the coulombian method with equivalent surface charges. Although these methods give very accurate results, they are not suitable for the study of magnetic couplings with iron-core structures.

An alternative analytical method to compute the torque for magnetic couplings with iron yokes is based on boundary value problems with Fourier analysis. This method consists in solving directly the Maxwell's equations in the different regions (air-gap, magnets....) by the separation of variables method [17], [18]. The magnetic field distribution is obtained in each region by using boundary and interface conditions. The torque and the force are then computed by using the Maxwell stress tensor. In [19] and [20], two-dimensional (2-D) analytical models for radial-type magnetic couplings were developed and closed-form expressions for the torque was given and used for design optimization. In [21] and [22], quasi 3-D analytical models are proposed to compute the performances of axial-flux permanent magnets machines. A 
modulation function is defined to take into account the radial dependence of the magnetic field.

In this paper, we propose new formulas for the torque and the axial force of an axial-type magnetic coupling with iron yokes (fig. 1). The analytical study is based on the solution of 2-D Laplace's and Poisson's equations in air-gap and permanent magnets regions by using the separation of variables method. The torque expression is used to study the influence of geometrical parameters (number of pole pairs and air-gap length). In order to study the accuracy of the proposed formulas, the results are compared with those obtained from 3 D finite elements simulations and experimental results.

\section{PROBLEM DESCRIPTION AND ASSUMPTIONS}

As shown in Fig. 1, the geometrical parameters of the studied magnetic coupling are the inner and outer radii of the magnets $R_{1}$ and $R_{2}$, the air gap length $e$, and the magnets thickness $h$. The pole-arc to pole-pitch ratio of the permanent magnets is $\alpha$. The number of pole-pairs is $p$.

Analytical study of axial magnetic couplings is complicated because of the three-dimensional nature of the magnetic field distribution. However, in order to simplify the analysis and to carry out closed-form expressions for the axial force and torque, the 3-D problem is reduced to a 2-D one by introducing a cylindrical cutting surface at the mean radius of the magnets $R_{e}=\left(R_{1}+R_{2}\right) / 2$ at which the magnetic field will be computed [21], [22].

Fig. 2 shows the resulting 2-D model by considering the unrolled cylindrical cutting surface. With this approach, we neglect the radial component of the magnetic field and we consider that the axial and tangential components do not depend on the $r$-coordinate. Moreover, for simplicity, we adopt the following assumptions:

1) The iron yokes have infinite magnetic permeability,

2) The magnets are axially magnetized with relative recoil permeability $\mu_{r}=1$.

As shown in Fig.2, the whole domain is divided into three regions: the PMs regions (regions I and III) and the air-gap region (region II). The magnets of region III are shifted by an angle $\delta$ (torque angle) from the magnets of region I. Due to the periodicity of the magnetic field distribution, the studied domain is limited by $0 \leq \theta \leq 2 \pi / p$.

A magnetic vector potential formulation is used in $2 \mathrm{D}$ cylindrical coordinates to describe the problem. According to the adopted assumptions, the magnetic vector potential in each region has only one component along the $r$-direction and only depends on the $\theta$ and $z$-coordinates. The electromagnetic equations in each region expressed in term of the magnetic vector potential are

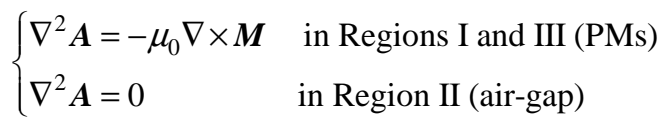

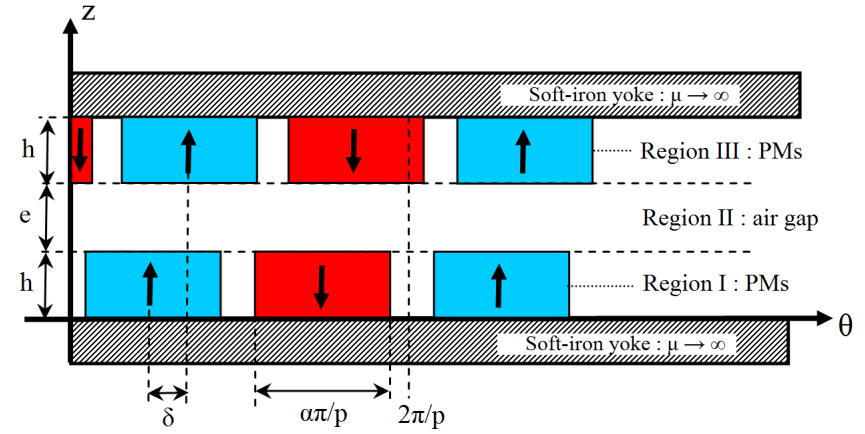

Fig. 2. 2-D model of the axial magnetic coupling at the mean radius of the magnets $R_{e}=\left(R_{1}+R_{2}\right) / 2$.

with

$$
\boldsymbol{M}=M_{z} \boldsymbol{e}_{z}= \pm \frac{B_{r}}{\mu_{0}} \boldsymbol{e}_{z}
$$

where $\boldsymbol{M}$ is the magnetization vector, $B_{r}$ the remanence of the magnets, $\boldsymbol{e}_{z}$ the unit vector along the axial direction and \pm indicates the magnetization direction.

\section{2-D ANALYTICAL MODEL}

By using the separation of variables method, we now consider the solution of Poisson's equations for PMs regions and Laplace's equation for the air-gap region.

\section{A. Solution of Poisson's Equation in the PMs Regions (Regions I and III)}

Poisson's equation in the magnets region (region III) can be written in a cylindrical coordinates system as

$$
\frac{1}{R_{e}^{2}} \frac{\partial^{2} A_{I I I}}{\partial \theta^{2}}+\frac{\partial^{2} A_{I I I}}{\partial z^{2}}=-\frac{\mu_{0}}{R_{e}} \frac{\partial M_{z}}{\partial \theta} \text { for }\left\{\begin{array}{l}
h+e \leq z \leq 2 h+e \\
0 \leq \theta \leq 2 \pi / p
\end{array}\right.
$$

where $\mu_{0}$ is the permeability of the vacuum and $M_{z}$ is the axial magnetization of the magnets.

Knowing that the tangential component of magnetic field at $z=2 h+e$ is null (soft-iron yoke with infinite permeability) and considering the continuity of the axial component of the flux density at $z=h+e$, we obtain the following boundary conditions

$$
\begin{gathered}
\left.\frac{\partial A_{I I I}}{\partial z}\right|_{z=2 h+e}=0 \\
A_{I I I}(\theta, h+e)=A_{I I}(\theta, h+e)
\end{gathered}
$$

where $A_{I I}(\theta, z)$ is the magnetic vector potential in the air-gap region.

The distribution of the axial magnetization $M_{z}$ is plotted in Fig. $3, \delta$ is the relative angular position between the magnets of region I and region III. The axial magnetization can be expressed in Fourier's series and replaced in (3) 


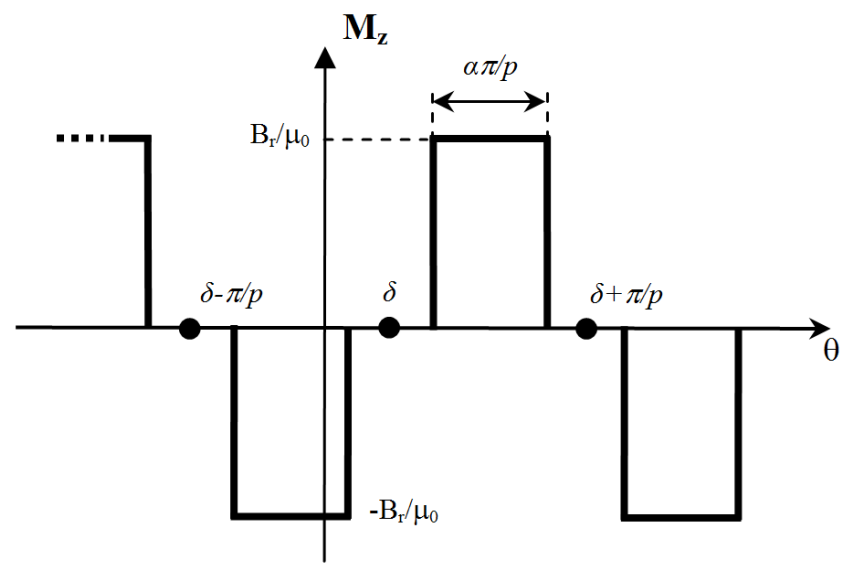

Fig. 3. Magnetization distribution along $\theta$-direction (region III).

$$
\begin{gathered}
M_{z}(\theta)=\sum_{k=1}^{\infty} M_{k} \sin (k p(\theta-\delta)) \\
M_{k}=\frac{4 B_{r}}{k \pi \mu_{0}} \cos \left(k \frac{\pi}{2}(1-\alpha)\right) \text { with } k=1,3,5,7 \ldots
\end{gathered}
$$

Taking into account the boundary conditions (4) and (5), the general solution of the magnetic vector potential in Region III can be written as

$$
\begin{aligned}
& A_{I I I}(\theta, z)= \\
& \sum_{k=1}^{\infty}\left(a_{k}^{I I I} \frac{\operatorname{ch}\left(\frac{k p}{R_{e}}(z-2 h-e)\right)}{\operatorname{ch}\left(\frac{k p}{R_{e}} h\right)}+K_{k} \cos (k p \delta)\right) \cos (k p \theta) \\
& +\sum_{k=1}^{\infty}\left(c_{k}^{I I I} \frac{\operatorname{ch}\left(\frac{k p}{R_{e}}(z-2 h-e)\right)}{c h\left(\frac{k p}{R_{e}} h\right)}+K_{k} \sin (k p \delta)\right) \sin (k p \theta)
\end{aligned}
$$

with

$$
K_{k}=\mu_{0} \frac{R_{e}}{k p^{2}} M_{k}
$$

The integration constants $a_{k}^{I I I}$ and $c_{k}^{I I I}$ are determined using a Fourier series expansion of $A_{I I}(\theta, h+e)$ over the interval $[0,2 \pi / \mathrm{p}]$

$$
\begin{aligned}
& a_{k}^{I I I}+K_{k} \cos (k p \delta)=\frac{2 p}{2 \pi} \int_{0}^{2 \pi / p} A_{I I}(\theta, h+e) \cos (k p \theta) d \theta \\
& c_{k}^{I I I}+K_{k} \sin (k p \delta)=\frac{2 p}{2 \pi} \int_{0}^{2 \pi / p} A_{I I}(\theta, h+e) \sin (k p \theta) d \theta
\end{aligned}
$$

The expressions of the coefficients $a_{k}^{I I I}$ and $c_{k}^{I I I}$ are given in the appendix.
One can apply the same procedure for region $I$ by considering a zero value for $\delta$. This leads to the following expression for the magnetic vector potential

$$
\begin{aligned}
A_{I}(\theta, z) & =\sum_{k=1}^{\infty}\left(a_{k}^{I} \frac{\operatorname{ch}\left(\frac{k p}{R_{e}} z\right)}{\operatorname{ch}\left(\frac{k p}{R_{e}} h\right)}+K_{k}\right) \cos (k p \theta) \\
& +\sum_{k=1}^{\infty} c_{k}^{I} \frac{\operatorname{ch}\left(\frac{k p}{R_{e}} z\right)}{\operatorname{ch}\left(\frac{k p}{R_{e}} h\right)} \sin (k p \theta)
\end{aligned}
$$

The integration constants $a_{k}^{I}$ and $c_{k}^{I}$ in (12) are determined using a Fourier series expansion of $A_{I I}(\theta, h)$ over the interval $[0,2 \pi / p]$

$$
\begin{aligned}
a_{k}^{I}+K_{k} & =\frac{2 p}{2 \pi} \int_{0}^{2 \pi / p} A_{I I}(\theta, h) \cos (k p \theta) d \theta \\
c_{k}^{I} & =\frac{2 p}{2 \pi} \int_{0}^{2 \pi / p} A_{I I}(\theta, h) \sin (k p \theta) d \theta
\end{aligned}
$$

The expressions of the coefficients $a_{k}^{I}$ and $c_{k}^{I}$ are given in the appendix.

\section{B. Solution of Laplace's Equation in the Air-Gap Region (Region II)}

Laplace's equation in the air-gap region can be written in a cylindrical coordinates system as

$$
\frac{1}{R_{e}^{2}} \frac{\partial^{2} A_{I I}}{\partial \theta^{2}}+\frac{\partial^{2} A_{I I}}{\partial z^{2}}=0 \text { for }\left\{\begin{array}{l}
h \leq z \leq h+e \\
0 \leq \theta \leq 2 \pi / p
\end{array}\right.
$$

The continuity of the tangential component of the magnetic field at $z=h$ and at $z=h+e$ leads to the following boundary conditions

$$
\left.\frac{\partial A_{I I}}{\partial z}\right|_{z=h}=\left.\frac{\partial A_{I}}{\partial z}\right|_{z=h} \text { and }\left.\frac{\partial A_{I I}}{\partial z}\right|_{z=h+e}=\left.\frac{\partial A_{I I I}}{\partial z}\right|_{z=h+e}
$$

By taking into account the boundary conditions (16), the general solution of the magnetic vector potential in the air-gap can be written as

$$
\begin{aligned}
& A_{I I}(\theta, z)= \\
& \sum_{k=1}^{\infty}\left(-a_{k}^{I I} \frac{R_{e}}{k p} \frac{\operatorname{ch}\left(\frac{k p}{R_{e}}(z-h-e)\right)}{\operatorname{sh}\left(\frac{k p}{R_{e}} e\right)}+b_{k}^{I I} \frac{R_{e}}{k p} \frac{\operatorname{ch}\left(\frac{k p}{R_{e}}(z-h)\right)}{\operatorname{sh}\left(\frac{k p}{R_{e}} e\right)}\right) \cos (k p \theta) \\
& +\sum_{k=1}^{\infty}\left(-c_{k}^{I I} \frac{R_{e}}{k p} \frac{\operatorname{ch}\left(\frac{k p}{R_{e}}(z-h-e)\right)}{s h\left(\frac{k p}{R_{e}} e\right)}+d_{k}^{I I} \frac{R_{e}}{k p} \frac{\operatorname{ch}\left(\frac{k p}{R_{e}}(z-h)\right)}{\operatorname{sh}\left(\frac{k p}{R_{e}} e\right)} \sin (k p \theta)\right.
\end{aligned}
$$


The integration constants $a_{k}^{I I}, \quad b_{k}^{I I}, \quad c_{k}^{I I}$ and $d_{k}^{I I}$ are determined using Fourier series expansions of $\partial A_{I} /\left.\partial z\right|_{h}$ and $\partial A_{I I I} /\left.\partial z\right|_{h+e}$ over the air-gap interval [0,2 $\left.\pi / p\right]$

$$
\begin{aligned}
& a_{k}^{I I}=\left.\frac{2 p}{2 \pi} \int_{0}^{2 \pi / p} \frac{\partial A_{I}}{\partial z}\right|_{h} \cos (k p \theta) d \theta \\
& b_{k}^{I I}=\left.\frac{2 p}{2 \pi} \int_{0}^{2 \pi / p} \frac{\partial A_{I I I}}{\partial z}\right|_{h+e} \cos (k p \theta) d \theta \\
& c_{k}^{I I}=\left.\frac{2 p}{2 \pi} \int_{0}^{2 \pi / p} \frac{\partial A_{I}}{\partial z}\right|_{h} \sin (k p \theta) d \theta \\
& d_{k}^{I I}=\left.\frac{2 p}{2 \pi} \int_{0}^{2 \pi / p} \frac{\partial A_{I I I}}{\partial z}\right|_{h+e} \sin (k p \theta) d \theta
\end{aligned}
$$

The expressions of these coefficients are developed in the appendix.

The axial and tangential components of the magnetic flux density in the air-gap can be deduced from the magnetic vector potential by

$$
B_{I I z}=-\frac{1}{R_{e}} \frac{\partial A_{I I}}{\partial \theta} \quad B_{I I \theta}=\frac{\partial A_{I I}}{\partial z}
$$

\section{AXIAL-FORCE AND TORQUE EXPRESSIONS}

\section{A. Electromagnetic torque}

The electromagnetic torque is obtained using the Maxwell stress tensor. A line at $z=\zeta \in[h, h+e]$ in the air-gap region is taken as the integration path so the electromagnetic torque is expressed as follows

$$
T_{e}=\frac{R_{2}^{3}-R_{1}^{3}}{3 \mu_{0}} \int_{0}^{2 \pi} B_{I I \theta}(\theta, \zeta) B_{I I z}(\theta, \zeta) d \theta
$$

Incorporating (22) into (23), the analytical expression for the electromagnetic torque becomes

$$
T_{e}=\frac{\pi\left(R_{2}^{3}-R_{1}^{3}\right)}{3 \mu_{0}} \sum_{k=1}^{\infty}\left(W_{k} X_{k}+Y_{k} Z_{k}\right)
$$

where the coefficients $W_{k}, X_{k}, Y_{k}$ and $Z_{k}$ are given in the appendix.

The torque can be computed with a good precision by considering only the fundamental components of the the flux density distribution in the air-gap $(k=1)$. This is especially true for large number of PM pole-pairs and/or large air-gap. Considering the first harmonic approximation, we can derive a closed-form expression for the electromagnetic torque which depends directly on the geometrical parameters.

$$
T_{e}=\frac{16}{3 \pi} \frac{B_{r}^{2}}{\mu_{0}} R_{2}^{3}\left(1-\left(\frac{R_{1}}{R_{2}}\right)^{3}\right) \sin ^{2}\left(\alpha \frac{\pi}{2}\right) \frac{\operatorname{sh}^{2} a}{\operatorname{sh}(2(1+v) a)} \sin (p \delta)
$$

with

$$
a=p \frac{h}{R_{e}} \quad \text { and } \quad v=\frac{e}{2 h}
$$

As expected, the torque presents a sinusoidal characteristic with the relative angular position $\delta$. Its maximum value (pullout torque) is obtained at the angle $\delta=\pi / 2 p$.

\section{B. Axial-Force}

Axial magnetic force is an important parameter for the design of an axial magnetic coupling. This attractive force must be known because it affects directly the rotor structure and bearings. Indeed, the bearing lifetime depends on the bearing load. By using the Maxwell stress tensor, the axial force expression is

$$
F=\frac{R_{2}^{2}-R_{1}^{2}}{4 \mu_{0}} \int_{0}^{2 \pi}\left(B_{I I z}^{2}(\theta, \zeta)-B_{I I \theta}^{2}(\theta, \zeta)\right) d \theta
$$

Substituting (22) into (27), the analytical expression for the axial force becomes

$$
F=\frac{\pi\left(R_{2}^{2}-R_{1}^{2}\right)}{4 \mu_{0}} \sum_{k=1}^{\infty}\left(\left(Z_{k}+X_{k}\right)^{2}-\left(W_{k}+Y_{k}\right)^{2}\right)
$$

Considering only the fundamental component of the magnetic field in the air-gap $(k=1)$, we can derive a closedform expression for the axial force

$$
\begin{aligned}
& F=\frac{8}{\pi} \frac{B_{r}^{2}}{\mu_{0}} R_{2}^{2}\left(1-\left(\frac{R_{1}}{R_{2}}\right)^{2}\right) \sin ^{2}\left(\alpha \frac{\pi}{2}\right) \frac{s^{2}(a)}{s h^{2}(2(1+v) a)} \\
& \times(\cos (p \delta) \operatorname{ch}(2(1+v) a)+1)
\end{aligned}
$$

From (25) and (29), we can see that the torque and the axial force dependence on the design parameters are explicit. For engineering purpose, it is important to have simple relations to study rapidly the effects of the geometrical parameters on the coupling performances. This is developed in the following subsection. 


\section{RESULTS OBTAINED WITH 2-D ANALYTICAL MODEL}

In this section, we use the proposed 2-D analytical model to compute the magnetic field distribution in the air-gap for different angular position between the two discs. For each position, the torque and the axial force are calculated by respectively using (25) and (29). Then, the influence of some geometrical parameters on the coupling performances is investigated (particularly the air-gap length and the pole-pairs number). The geometrical parameters of the studied device are given in Table I. These parameters correspond to the one which give a pull-out torque of around $90 \mathrm{Nm}$ (obtained using (25)) when we consider an air-gap length of $3 \mathrm{~mm}$ and a 6 pole-pairs.

\section{A. Flux density distribution and torque calculation for $e=$} $3 m m$ and $p=6$

Figs. $4 \mathrm{a}$ and $4 \mathrm{~b}$ show respectively the flux lines (for two pole pitches) and the axial component of the flux density in the middle of the air-gap under no-load condition $\left(\delta=0^{\circ}\right)$. The magnetic flux density distribution along the air-gap is computed by using (17) and (22). We can observe that the flux lines are almost axial along the air-gap (the tangential component of the flux density is null in the middle of the airgap). For this position, the torque is then equal to zero and the axial force is attractive and reaches its maximum value. By using (29), we obtain $F \approx 2500 \mathrm{~N}$ as shown in Fig. 8 .

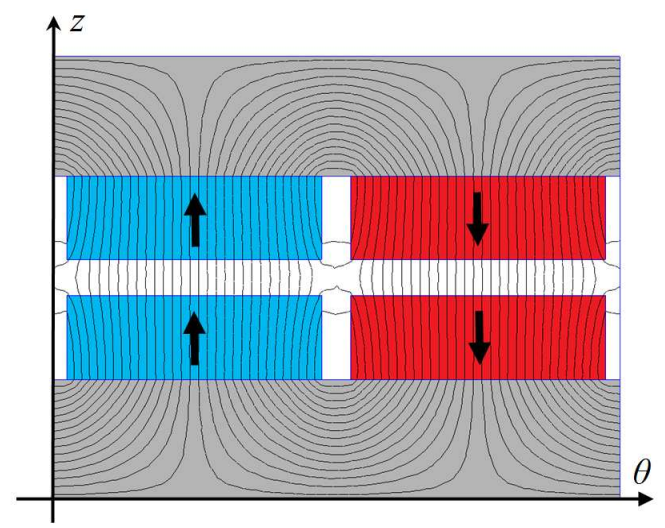

(a)

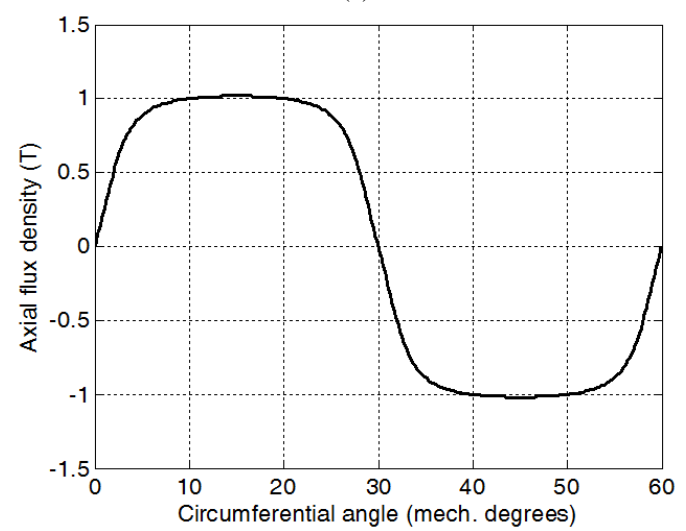

(b)

Fig. 4. No load condition $\left(\delta=0^{\circ}\right)$ : (a) magnetic flux lines, (b) axial component of the flux density in the middle of the air-gap.
Fig. 5 corresponds to the full load condition $\left(\delta=15^{\circ}\right)$. We can observe clearly on Fig. 5a the distortion of the flux lines due to the angular displacement of the upper magnets. Fig. 5b and Fig. 5c show respectively the axial and the tangential components of the flux density in the middle of the air-gap. For this angular position, the torque reaches its maximum value $T_{e}=94 \mathrm{Nm}$ (pull-out torque) as indicated in fig. 7 and the axial force is still attractive $(F=423 \mathrm{~N})$ as shown in fig. 8 . As it can be observed in fig. 8 , the axial force reaches a null value for an angle slightly higher to half the pole pitch (around $\left.17^{\circ}\right)$.

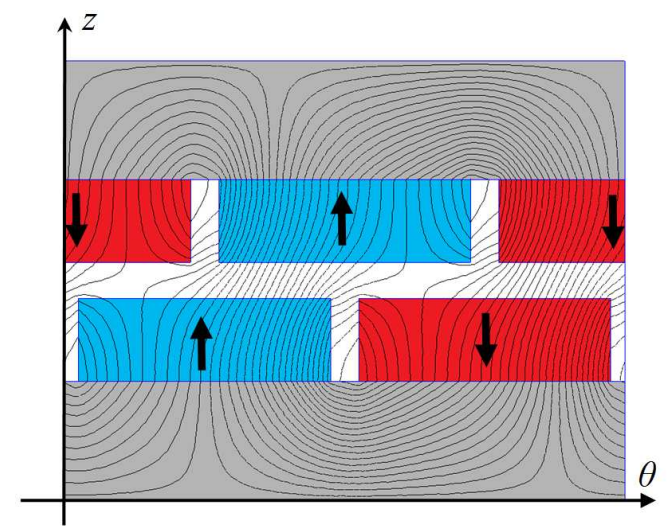

(a)

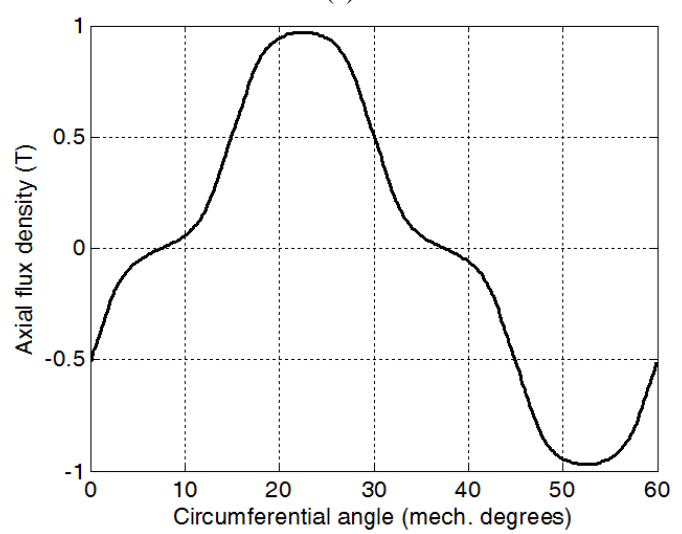

(b)

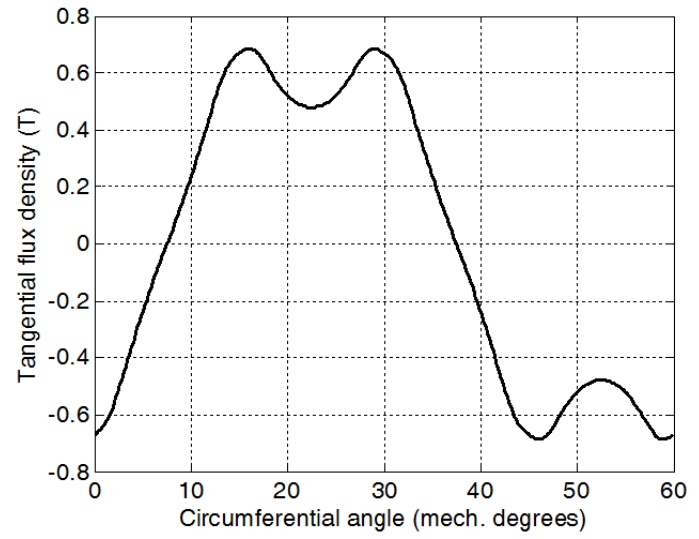

(c)

Fig. 5. Full load condition $\left(\delta=15^{\circ}\right)$ : (a) magnetic flux lines, (b) axial component of the flux density, (c) tangential component of the flux density. 
Fig. 6 corresponds to an angular displacement $\delta=30^{\circ}$ (unstable position). In this position, the magnets of the two discs are in opposed direction and the flux lines repel each other. The flux density presents only a tangential component in the middle of the air-gap. The torque is then equal to zero and the axial force is now repulsive as shown in fig. 8. The axial force value computed with (29) gives $F=-1628 \mathrm{~N}$.

Fig. 7 and Fig. 8 summarize the variation of torque and axial force as a function of the angular displacement $\delta$. As shown previously, the maximum torque occurs at an angular shifting of half pole pitch angle. We can observe that the first harmonic approximation gives accurate results (the error is less than 5\%) compared to the ones obtained by taking into account 10 harmonic terms in (24) and (28).

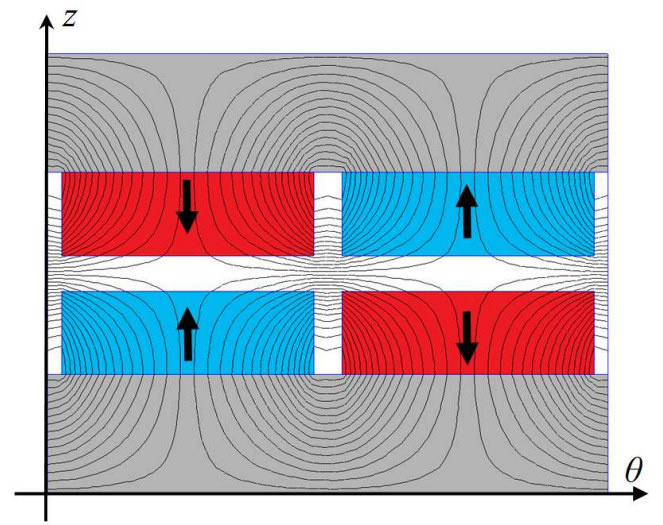

(a)

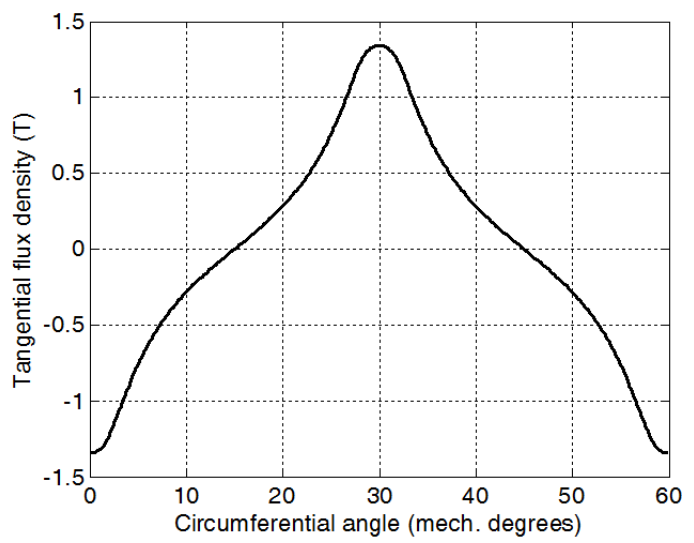

(b)

Fig. 6. Magnets in opposed direction $\left(\delta=30^{\circ}\right.$ ): (a) magnetic flux lines, (b) tangential component of the flux density in the middle of the air-gap.

TABLE I

PARAMETERS OF THE STUDIED AXIAL COUPLING

\begin{tabular}{lll}
\hline \hline \multirow{2}{*}{ Symbol } & \multicolumn{1}{c}{ Quantity } & \multicolumn{1}{c}{ value } \\
& & $30 \mathrm{~mm}$ \\
$R_{1}$ & Inner radius of the magnets & $60 \mathrm{~mm}$ \\
$R_{2}$ & Outer radius of the magnets & $7 \mathrm{~mm}$ \\
$h$ & Magnets thickness & variable \\
$e$ & Air-gap length & 0.9 \\
$\alpha$ & PMs pole-arc to pole-pitch ratio & variable \\
$p$ & Pole-pairs number & $1.25 \mathrm{~T}$ \\
$B_{r}$ & Remanence of the permanent magnets & \\
\hline
\end{tabular}

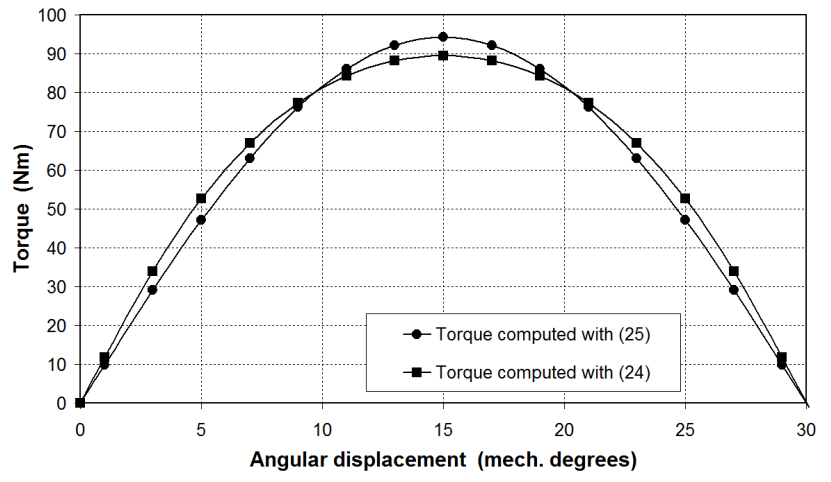

Fig. 7. Torque versus the angular displacement $\delta$ for $e=3 \mathrm{~mm}$ and $p=6$.

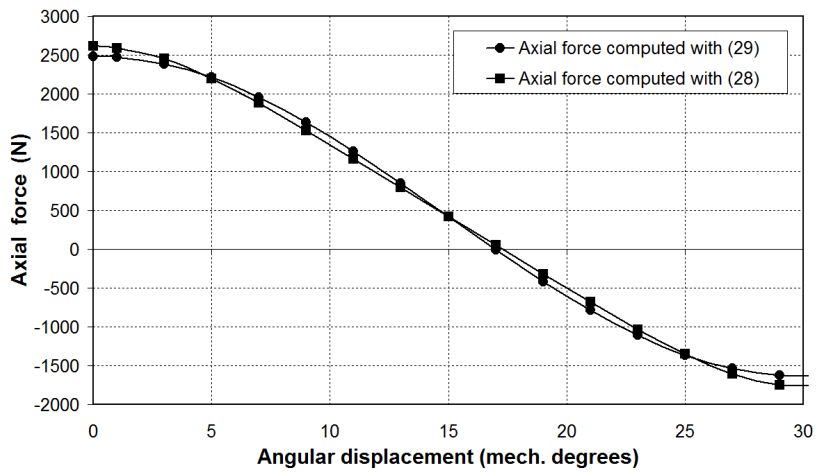

Fig. 8. Axial force versus the angular displacement $\delta$ for $e=3 \mathrm{~mm}$ and $p=6$.

\section{B. Influence of the air-gap length}

The length of the air-gap has a significant influence on the characteristics of the axial magnetic coupling. Fig. 9 and Fig. 10 show respectively the pull-out torque and the maximal axial force as a function of the air-gap length. The results have been computed by using (25) and (29). The geometrical parameters are the ones given in table I and we have considered a number of pole pairs $p=6$. As shown in fig. 9, the pull-out torque of the magnetic coupling decreases quickly as the distance between the magnets increases. The maximum torque is almost divided by two when the air-gap is increased from $2 \mathrm{~mm}$ to $7 \mathrm{~mm}$. In the same way, the maximal axial force is reduced when the air-gap length increases (fig. 10).

\section{Influence of the number of pole pairs}

The variation of pull-out torque and maximal axial force versus the number of pole pairs are respectively shown in fig. 11 and fig. 12. The results have been computed by using (25) and (29). For the study, we have considered several air-gap lengths. The other geometrical parameters are those given in Table I. Fig. 11 shows that all the curves present a maximum which depends on the air-gap length. The optimum value of the number of pole pairs is shifted to the right when the air-gap is reduced. This result is well known for magnetic couplings. For the studied coupling (Table I), the optimal number of pole pairs is $p=6$ if we consider an air-gap length $e=5 \mathrm{~mm}$. We can observe in Fig. 12 that the maximum axial force decreases when the number of pole pairs increases. 
We have shown here that the torque formula (25) can predict the effects of the geometrical parameters on the coupling performances and from fig. 11, we can choose rapidly the optimum value of the number of pole pairs when the other geometrical parameters are given.

In the next subsection, we investigate the precision of the 2D approximation (25), by comparing the previous analytical results with 3-D FEM simulations and experimental results.

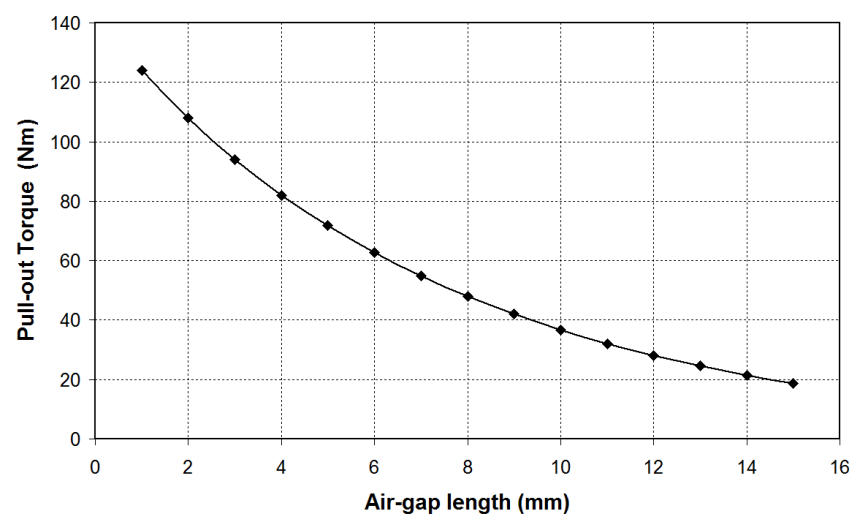

Fig. 9. Pull-out torque versus air-gap length for $p=6$.

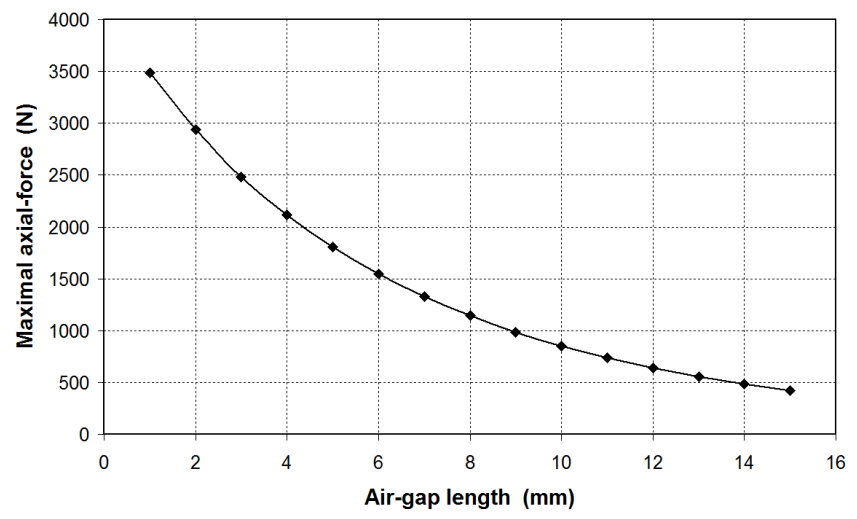

Fig. 10. Maximum axial-force versus air-gap length for $p=6$.

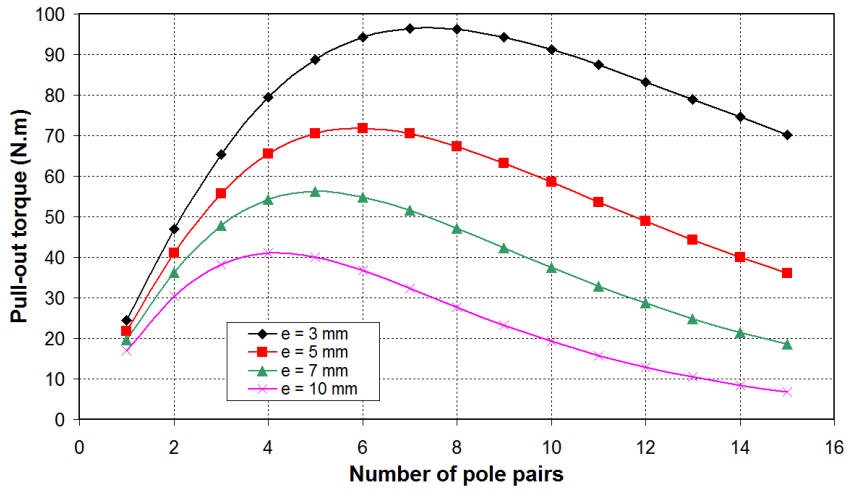

Fig. 11. Pull-out torque versus the number of pole pairs for several air-gap values.

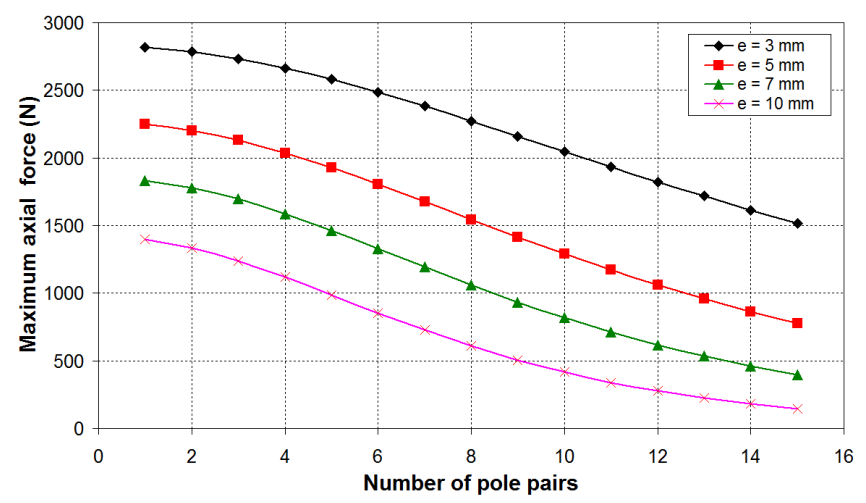

Fig. 12. Maximum axial force versus the number of pole pairs for several airgap values.

\section{3-D FEM SIMULATIONS AND EXPERIMENTAL RESULTS}

In order to show the limits of the formulas (25) and (29), the analytical results have been compared to 3-D FEM simulations in one hand and to experimental results in another hand. For the 3-D finite element simulations, we have used COMSOL multiphysics software.

For the experimental validation, we have manufactured an axial magnetic coupling prototype using sector type $\mathrm{NdFeB}$ magnets glued on iron yokes. The geometrical parameters of the prototype are those of Table I. We choose a number of pole pairs $p=6$ that corresponds practically to the optimum value for an air-gap value $e=5 \mathrm{~mm}$.

Fig. 13 shows the axial magnetic coupling placed on the test bench. The axial coupling is inserted between two electrical machines. In fig. 13, the air-gap value is $e=9.5 \mathrm{~mm}$.

\section{A. 3-D FEM results}

Fig. 14 and Fig. 15 show respectively the pull-out torque and the maximal axial force as a function of the air-gap length obtained with 3-D finite elements analysis and with the 2-D analytical model. The number of harmonic terms used in (24) and (28) is $\mathrm{N}=10$. The geometrical parameters are those given in Table I. For this study, the pole pair number is fixed to $p=6$. As expected for this type of device, the 2-D analytical prediction gives higher values for both pull-out torque and maximal axial force as compared to 3-D FE analysis.

This is mainly due to the 3-D effects which are not taken into account in the proposed model (the radial dependence of the magnetic field is not considered). The error on the pull-out torque prediction ranges from $22 \%$ for $e=2 \mathrm{~mm}$ to $37 \%$ for $e=12 \mathrm{~mm}$. The error on the maximal axial force prediction is less important and ranges from $8 \%$ for $e=2 \mathrm{~mm}$ to $34 \%$ for $e=12 \mathrm{~mm}$.

Figs. 16 show the pull-out torque versus the number of pole pairs computed with 3 methods ((24), (25) and3-D FEM). The results are given for three values of the air-gap lengths. As it can be observed in Figs. 16, although the analytical formula (25) predicts higher torque values, the number of pole pairs which corresponds to the maximal value of the torque is almost the same for the 3 methods in use. 


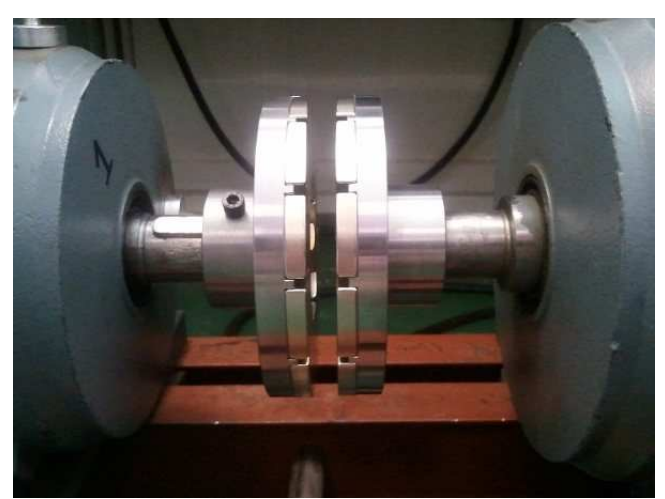

Fig. 13. Axial magnetic coupling prototype placed on the test bench $(e=$ $9.5 \mathrm{~mm})$.

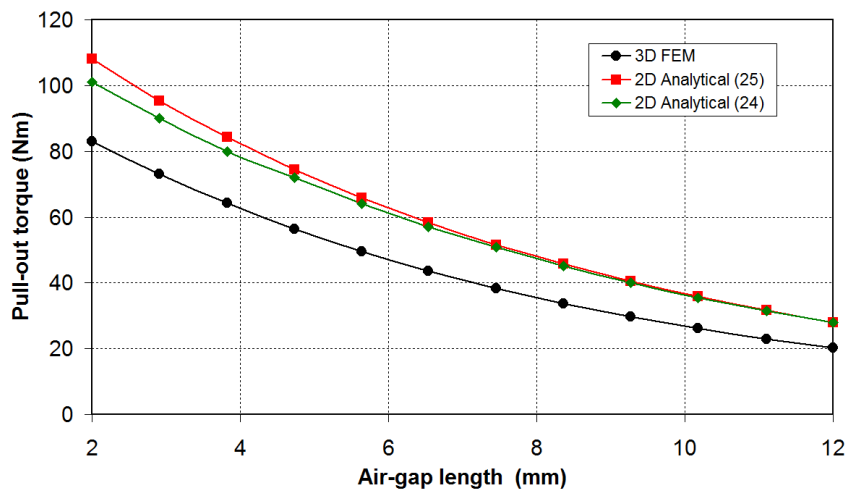

Fig. 14. Pull-out torque versus the air-gap length for $p=6$ : 3-D FEM and 2-D analytical results.

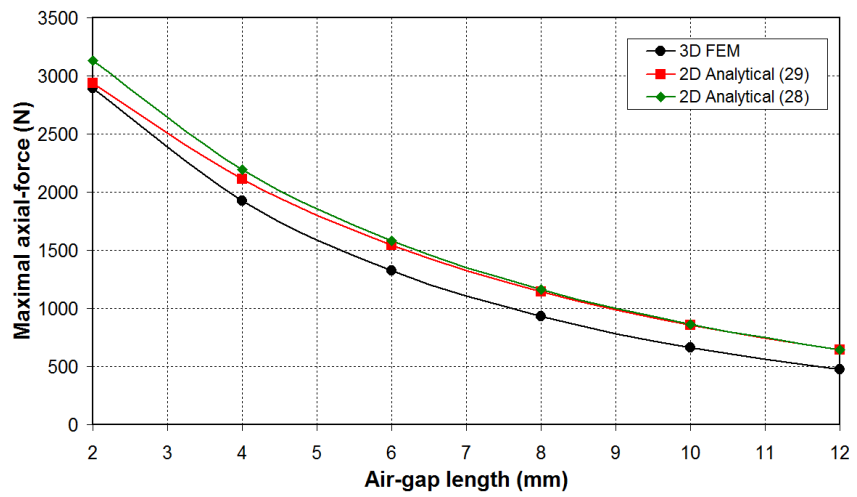

Fig. 15. Maximum axial-force versus the air-gap length for $p=6$, 3-D FEM and 2-D analytical results.

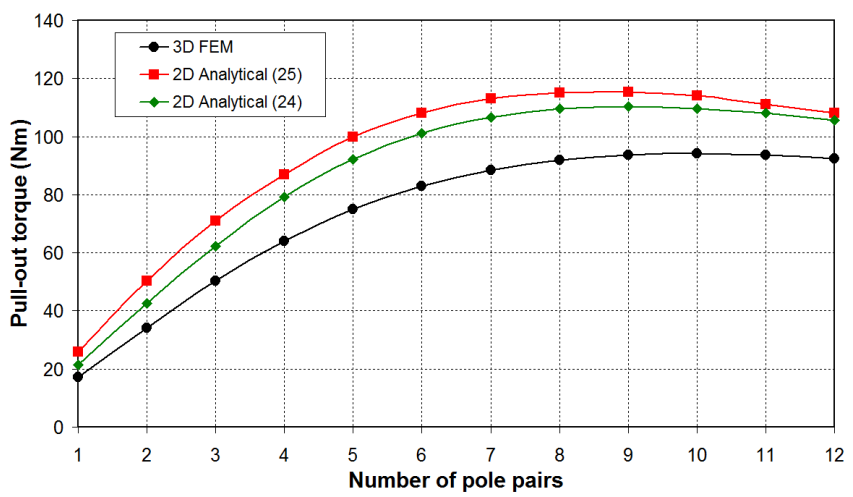

(a)

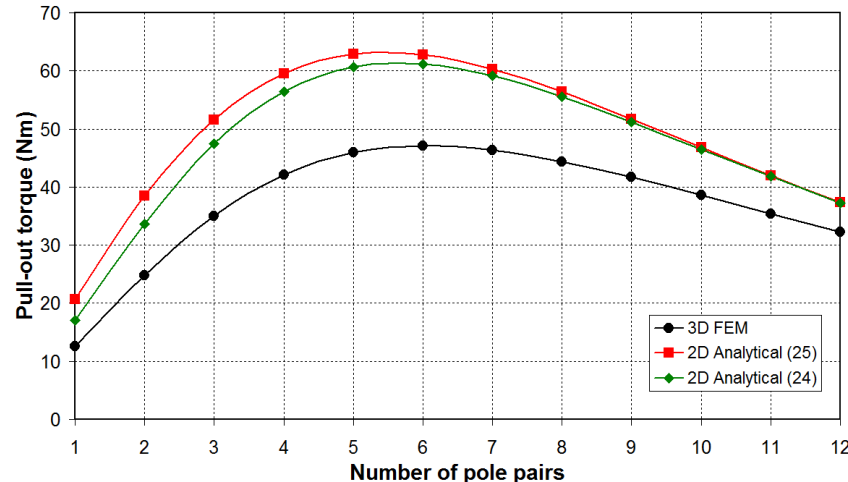

(b)

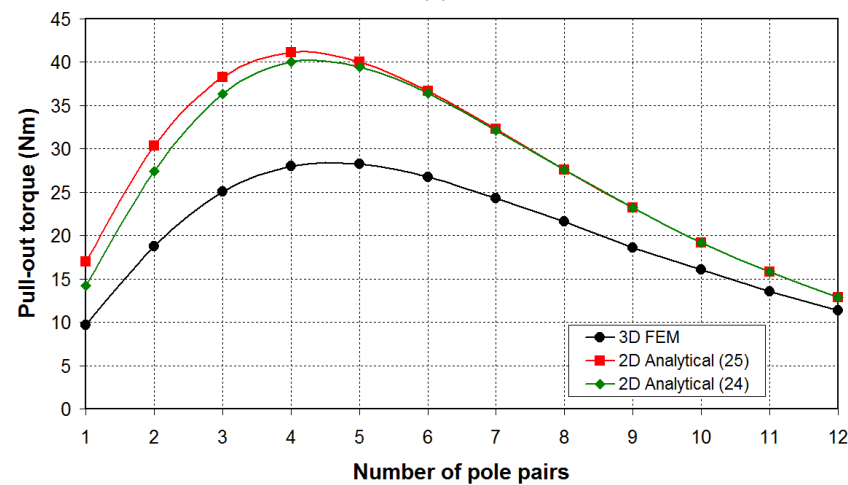

(c)

Fig. 16. Pull-out torque versus the number of pole pairs obtained with 3-D FEM and 2-D analytical model: (a) $e=2 \mathrm{~mm}$; (b) $e=6 \mathrm{~mm}$; (c) $e=10 \mathrm{~mm}$.

Fig. 17 presents the synthesis of Fig. 16 and gives the optimal value of the pole-pair number versus air-gap lengths. This is an important result since we can observe in fig. 17 that the analytical formula (25) is suitable in the determination of the optimum value of the pole-pair number with the air-gap value when the other geometrical parameters are fixed.

\section{B. Experimental results}

Fig. 18 compares the measured values of the axial flux density and the ones obtained with the proposed $2 \mathrm{D}$ analytical model for no load condition $(\delta=0)$. The measurements are made along the $\theta$ coordinate at the mean radius of the magnets $R_{e}=45 \mathrm{~mm}$. For this test, the air-gap is fixed at $e=9.5 \mathrm{~mm}$. A Hall probe placed on a XY table is used to measure the magnetic field distribution. As the magnetic flux density is measured at the mean radius $R_{e}$, we can observe very good agreement between experimental results and the ones obtained with the 2-D analytical model.

To show the limits of the 2-D analytical model, we have measured the radial dependence of the axial flux density at a center line of a pole for no-load condition $(\delta=0)$. The air-gap is fixed at $e=9.5 \mathrm{~mm}$. The results are shown in fig. 19. As it can be observed, the axial flux density shows large variations along the radial expanse of the magnet. This is due to the large value of the air-gap. This result can not be predicted by the 2$\mathrm{D}$ analytical model which neglects the radial dependence of the magnetic field. We can note a good agreement between 3D FEM simulations and experimental results. 


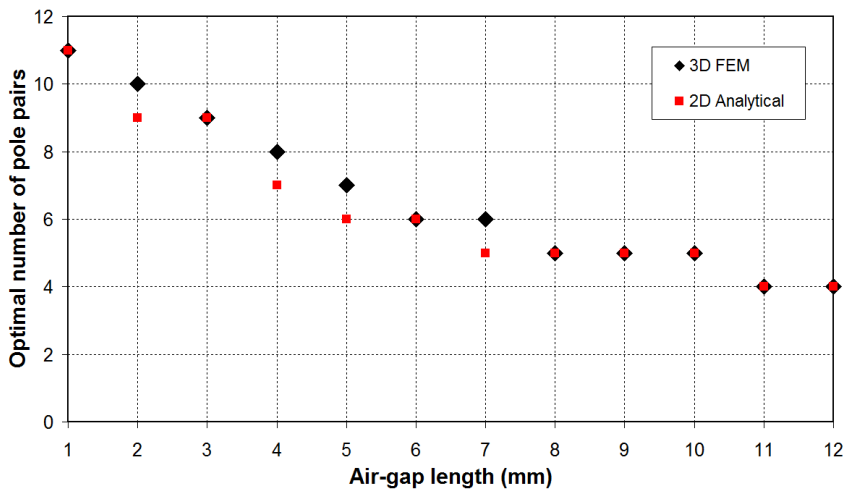

Fig. 17. Optimal value of the pole-pair number versus air-gap dimension computed with 3-D FEM and 2-D analytical model (25).

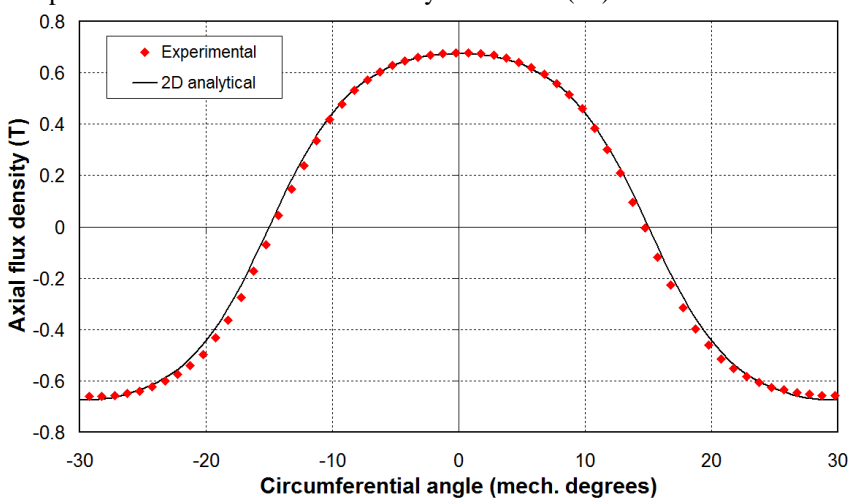

Fig. 18. Measured and computed (2D analytical model) axial flux density in the middle of the air-gap at the mean radius $R_{e}=\left(R_{1}+R_{2}\right) / 2$ for $e=9.5 \mathrm{~mm}$.

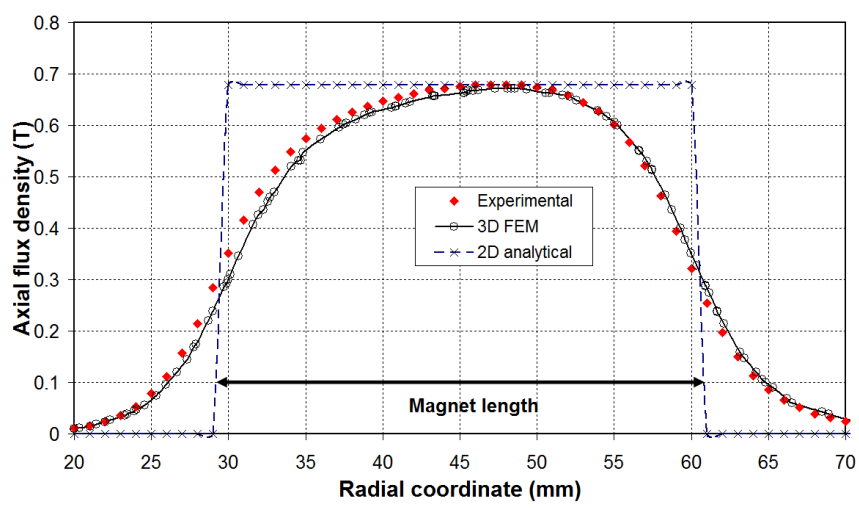

Fig. 19. Measured and computed axial flux density along a radial lines in the middle of the air-gap at a center line of a pole for $e=9.5 \mathrm{~mm}$.

Figs. 20 show the comparison between the measured values of the static torque and the calculated ones by using the 2-D analytical model (25) and 3-D FEM. The static torque was measured by suspending weights from a wire attached to a rod (a rotor is locked and the other one can rotate). The relative angular position $\delta$ was measured using an encoder with a resolution of 4096 steps per revolution (0.088 degree). Two values of the air-gap dimension were considered $(e=4 \mathrm{~mm}$ and $e=9.5 \mathrm{~mm})$. It can be noticed that the experimental measurements are in good agreement with the results obtained with 3-D FE simulations. As shown previously, analytical formula (25) gives higher values of around 30\% for the pullout torque.

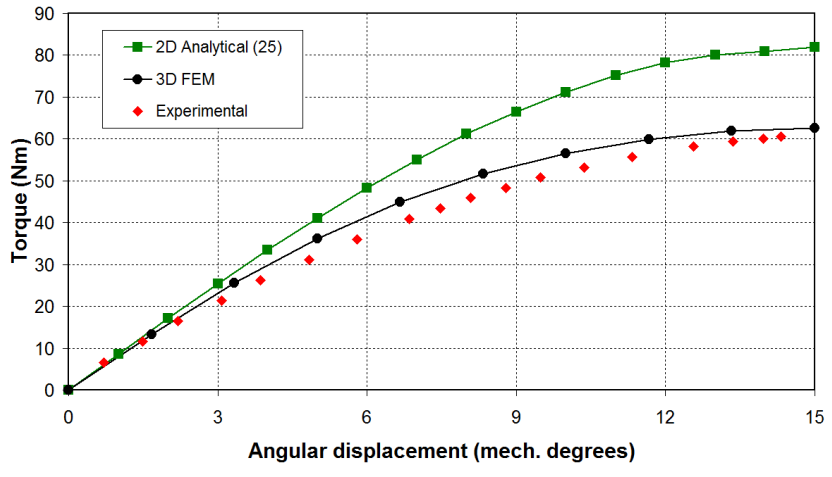

(a)

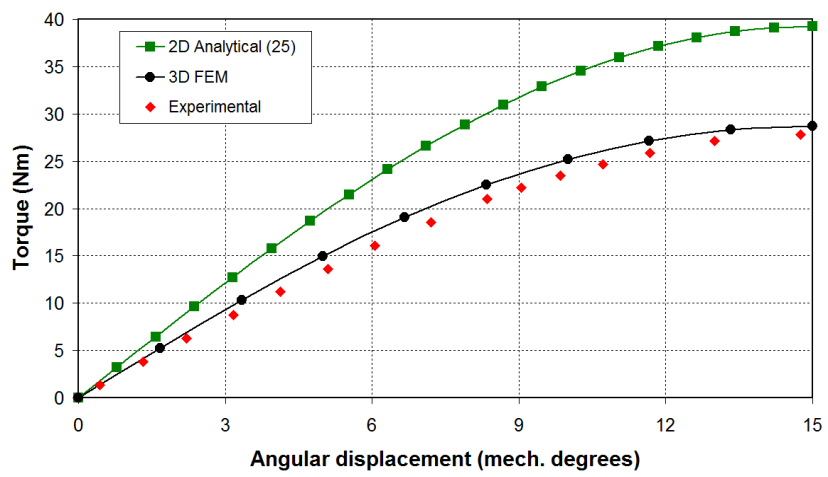

(b)

Fig. 20. Measured and computed static torque versus the angular displacement $\delta$ for $p=6$ : (a) $e=4 \mathrm{~mm}$; (b) $e=9.5 \mathrm{~mm}$

\section{CONCLUSION}

In this paper, we have proposed new simple analytical expressions for computing axial force and torque of an axial magnetic coupling. These expressions are determined by the solution of 2-D Laplace's and Poisson's equations (mean radius model) in the different regions (air-gap and magnets).

Although the proposed 2D analytical model shows some lack of accuracy compared to 3D finite-element simulations and experimental results (error of around $30 \%$ on the pull-out torque prediction), we have shown that it can be used to determine rapidly the optimal value of the pole-pair number when the other geometrical parameters are given.

Moreover, the proposed analytical formulas can be useful tools for the first step of design optimization since continuous derivatives issued from the analytical expressions are of great importance in most optimization methods.

\section{APPENDIX}

- The development of (10) and (11) gives

$$
\begin{aligned}
& a_{k}^{I I I}+K_{k} \cos (k p \delta)=-a_{k}^{I I} \frac{R_{e}}{k p} \frac{1}{\operatorname{sh}\left(\frac{k p}{R_{e}} e\right)}+b_{k}^{I I} \frac{R_{e}}{k p} \frac{\operatorname{ch}\left(\frac{k p}{R_{e}} e\right)}{\operatorname{sh}\left(\frac{k p}{R_{e}} e\right)} \\
& c_{k}^{I I I}+K_{k} \sin (k p \delta)=-c_{k}^{I I} \frac{R_{e}}{k p} \frac{1}{\operatorname{sh}\left(\frac{k p}{R_{e}} e\right)}+d_{k}^{I I} \frac{R_{e}}{k p} \frac{\operatorname{ch}\left(\frac{k p}{R_{e}} e\right)}{\operatorname{sh}\left(\frac{k p}{R_{e}} e\right)}
\end{aligned}
$$


The development of (13) and (14) gives

$$
\begin{gathered}
a_{k}^{I}+K_{k}=-a_{k}^{I I} \frac{R_{e}}{k p} \frac{\operatorname{ch}\left(\frac{k p}{R_{e}} e\right)}{\operatorname{sh}\left(\frac{k p}{R_{e}} e\right)}+b_{k}^{I I} \frac{R_{e}}{k p} \frac{1}{\operatorname{sh}\left(\frac{k p}{R_{e}} e\right)} \\
c_{k}^{I}=-c_{k}^{I I} \frac{R_{e}}{k p} \frac{\operatorname{ch}\left(\frac{k p}{R_{e}} e\right)}{\operatorname{sh}\left(\frac{k p}{R_{e}} e\right)}+d_{k}^{I I} \frac{R_{e}}{k p} \frac{1}{\operatorname{sh}\left(\frac{k p}{R_{e}} e\right)}
\end{gathered}
$$

- Expressions of the coefficients $a_{k}^{I I}, b_{k}^{I I}, c_{k}^{I I}$ and $d_{k}^{I I}$ for the air-gap region

The development of (18) to (21) gives

$$
\begin{array}{ll}
a_{k}^{I I}=a_{k}^{I} \frac{k p}{R_{e}} t h\left(\frac{k p}{R_{e}} h\right) & b_{k}^{I I}=-a_{k}^{I I I} \frac{k p}{R_{e}} t h\left(\frac{k p}{R_{e}} h\right) \\
c_{k}^{I I}=c_{k}^{I} \frac{k p}{R_{e}} t h\left(\frac{k p}{R_{e}} h\right) & d_{k}^{I I}=-c_{k}^{I I I} \frac{k p}{R_{e}} t h\left(\frac{k p}{R_{e}} h\right)
\end{array}
$$

- Expression of the coefficients $W_{k}, X_{k}, Y_{k}$ and $Z_{k}$ given in (24) and (28)

$$
\begin{gathered}
W_{k}=-a_{k}^{I I} \frac{\operatorname{sh}\left(\frac{k p}{R_{e}}(\zeta-h-e)\right)}{s h\left(\frac{k p}{R_{e}} e\right)}+b_{k}^{I I} \frac{\operatorname{sh}\left(\frac{k p}{R_{e}}(\zeta-h)\right)}{s h\left(\frac{k p}{R_{e}} e\right)} \\
X_{k}=c_{k}^{I I} \frac{\operatorname{ch}\left(\frac{k p}{R_{e}}(\zeta-h-e)\right)}{s h\left(\frac{k p}{R_{e}} e\right)}-d_{k}^{I I} \frac{R_{e}}{k p} \frac{\operatorname{ch}\left(\frac{k p}{R_{e}}(\zeta-h)\right)}{s h\left(\frac{k p}{R_{e}} e\right)} \\
Y_{k}=-c_{k}^{I I} \frac{\operatorname{sh}\left(\frac{k p}{R_{e}}(\zeta-h-e)\right)}{s h\left(\frac{k p}{R_{e}} e\right)}+d_{k}^{I I} \frac{R_{e}}{k p} \frac{\operatorname{sh}\left(\frac{k p}{R_{e}}(\zeta-h)\right)}{s h\left(\frac{k p}{R_{e}} e\right)} \\
Z_{k}=-a_{k}^{I I} \frac{\operatorname{ch}\left(\frac{k p}{R_{e}}(\zeta-h-e)\right)}{\operatorname{sh}\left(\frac{k p}{R_{e}} e\right)}+b_{k}^{I I} \frac{\operatorname{ch}\left(\frac{k p}{R_{e}}(\zeta-h)\right)}{s h\left(\frac{k p}{R_{e}} e\right)}
\end{gathered}
$$

\section{REFERENCES}

[1] J. P. Yonnet, "Permanent magnet bearings and couplings," IEEE Trans. Magn., vol. 17, no. 1, pp. 1169-1173, 1981.

[2] E. P. Furlani, "Formulas for the force and torque of axial couplings," IEEE Trans. Magn., vol. 29, no. 5, pp. 2295-2301, Sep. 1993.

[3] J. P. Yonnet, S. Hemmerlin, E. Rulliere, and G. Lemarquand, "Analytical calculation of permanent magnet couplings," IEEE Trans. Magn., vol. 29, no. 6, pp. 2932-2934, Nov. 1993.

[4] E. Furlani, S. Reznik, and A. Kroll, "A three-dimensional field solution for radially polarized cylinders," IEEE Trans. Magn., vol. 31, no. 1, pp. 844-851, Jan. 1995.

[5] E. P. Furlani, R. Wang, and H. Kusnadi, "A three-dimensional model for computing the torque of radial couplings," IEEE Trans. Magn., vol. 31, no. 5, pp. 2522-2526, Sep. 1995.

[6] Y. D. Yao, G. J. Chiou, D. R. Huang, and S. J. Wang, "Theoretical computations for the torque of magnetic coupling," IEEE Trans. Magn., vol. 31, no. 3, pp. 1881-1884, May. 1995.

[7] R. Waring, j. Hall, K. Pullen, and M. R. Etemad, "An investigation of face type magnetic couplers," Proc. Inst. Mech. Engrs, Part. A., vol. 210, no. 4, pp. 263-272, 1996.
[8] E. P. Furlani, "Analysis and optimization of synchronous couplings," $J$. Appl. Phys., vol. 79, pp. 4692-4694, 1996.

[9] E. P. Furlani and M. A. Knewtson, "A three-dimensional field solution for permanent-magnet axial-field motors," IEEE Trans. Magn., vol. 33, no. 3, pp. 2322-2325, May. 1997.

[10] P. Elies and G. Lemarquand, "Analytical optimization of the torque of a permanent-magnet coaxial synchronous coupling," IEEE Trans.Magn., vol. 34, no. 4, pp. 2267-2273, Jul. 1998.

[11] J. F. Charpentier and G. Lemarquand, "Optimal design of cylindrical air-gap synchronous permanent magnet couplings," IEEE Trans.Magn., vol. 35, no. 2, pp. 1037-1046, Mar. 1999.

[12] J. F. Charpentier, N. Fadli, and J. Jennane, "Study of ironless permanent magnet devices being both a coupling and an axial bearing for naval propulsion," IEEE Trans. Magn., vol. 39, no. 5, pp. 3235-3237, Sep. 2003.

[13] H. L. Rakotoarison, J. P. Yonnet, and B. Delinchant., "Using Coulombian approach for modelling scalar potential and magnetic field of a permanent magnet with radial polarization," IEEE Trans. Magn., vol. 43, no. 4, pp. 1261-1264, Apr. 2007.

[14] R. Ravaud and G. Lemarquand, "Comparison of the Coulombian and Amperian current models for calculating the magnetic field produced by arc-shaped permanent magnets radially magnetized," Prog. Electromagn. Res., vol. 95, pp. 309-327, 2009.

[15] R. Ravaud, G. Lemarquand, V. Lemarquand, and C. Depollier, "Permanent magnet couplings: Field and torque three-dimensional expressions based on the Coulombian model," IEEE Trans. Magn., vol. 45, no. 4, pp. 1950-1958, Apr. 2009.

[16] R. Ravaud, V. Lemarquand, and G. Lemarquand, "Analytical design of permanent magnet radial couplings," IEEE Trans. Magn., vol. 46, no. 11 , pp. 3860-3865, Nov. 2010.

[17] B. L. J. Gysen, K. J. Meessen, J. J. H. Paulides, and E. A. Lomonova, "General formulation of the electromagnetic field distribution in machines and devices using Fourier analysis," IEEE Trans. Magn., vol. 46, no. 1, pp. 39-52, Jan. 2010.

[18] T. Lubin, S. Mezani, and A. Rezzoug, "Exact analytical method for magnetic field computation in the air-gap of cylindrical electrical machines considering slotting effects," IEEE Trans. Magn., vol. 46, no. 4, pp. 1092-1099, Apr. 2010.

[19] R. M. Hornreich and S. Shtrikman, "Optimal design of synchronous torque couplers," IEEE Trans. Magn., vol. 14, no. 5, pp. 800-802, Sept. 1978.

[20] J. Fontchastagner, Y Lefèvre, and F. Messine, "Some co-axial magnetic couplings designed using an analytical model and an exact global optimization code," IEEE Trans. Magn., vol. 45, no. 3, pp. 1458-1461, Mar. 2009.

[21] A. Parviainen, M. Niemelä, and J. Pyrhönen, "Modeling of axial flux permanent-magnet machines," IEEE Trans. Ind. Appl., vol. 40, no. 5, pp. 1333-1340, Sep./Oct. 2004.

[22] J. Azzouzi, G. Barakat, and B. Dakyo, "Quasi-3-D analytical modeling of the magnetic field of an axial flux permanent-magnet synchronous machine," IEEE Trans. Energy. Convers., vol. 20, no. 4, pp. 746-752, Dec. 2005.

[23] C. Ferreira and J. Vaidya, "Torque analysis of permanent magnet coupling using 2D and 3D finite elements methods," IEEE Trans. Magn., vol. 25, pp. 3080-3082, Jul. 1989.

[24] W. Wu, H. C. Lovatt, and J. C.Dunlop, "Analysis and design optimisation of magnetic couplings using 3D finite element modelling," IEEE Trans. Magn., vol. 33, no. 5, pp. 4083-4085, Sept. 1997.

[25] R. Wang, E. P. Furlani, and Z. J. Cendes, "Design and analysis of a permanent magnet axial coupling using 3D finite element field computations," IEEE Trans. Magn., vol. 30, no. 4, pp. 2292-2295, Jul. 1994.

[26] T. F. Chan, W. Wang, and L. L. Lai, "Performance of an Axial-Flux Permanent Magnet Synchronous Generator From3-D Finite-Element Analysis," IEEE Trans. Energy. Convers., vol. 25, no. 3, pp. 669-676, Sep. 2010. 


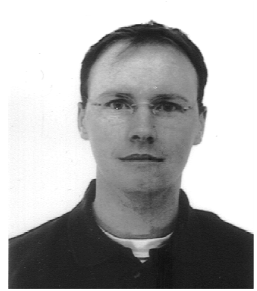

electrical devices.

Thierry Lubin was born in Sedan, France, in 1970. He received the M.S. degree from the University Pierre et Marie Curie, Paris 6, France in 1994 and the Ph.D. degree from the University Henri Poincaré, Nancy, France, in 2003.

$\mathrm{He}$ is currently a lecturer of Electrical Engineering at the University of Nancy at the Groupe de Recherche en Electrotechnique et Electronique de Nancy. His interests include modeling and control of electrical machines, and applied superconductivity in

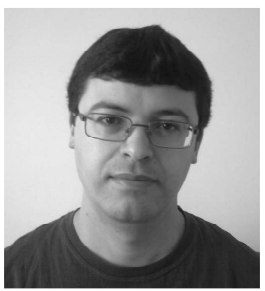

Smail Mezani was born in Algiers, Algeria, in 1974. He received the engineer diploma and the magister degree from the University of Sciences and Technology Houari Boumediene, Algiers, Algeria in 1996 and 1999 respectively. He obtained

the Ph.D. degree from the Institut National Polytechnique de Lorraine, France, in 2004.

$\mathrm{He}$ is currently a lecturer at the University Henri Poincaré of Nancy, France, at the Groupe de Recherche en Electrotechnique et Electronique de Nancy where his research interests include the applications of superconductors in electromechanical devices.

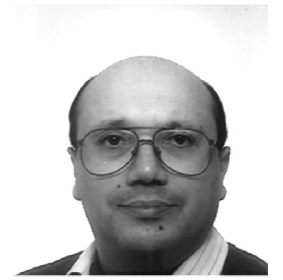

Abderrezak Rezzoug received the electrical engineer degree from ENSEM INPL, Nancy, France in 1972, and the Dr. Ing. diploma and the Ph.D. degree from INPL, in 1979 and 1987 respectively.

After working at the INPL as an assistant Professor until 1991, he is currently a Professor of Electrical Engineering at the University Henri Poincaré, Nancy, France. As a member of the Groupe de Recherche en Electrotechnique et Electronique de Nancy, his main subjects of research concern superconducting applications to electrical devices, and the control and diagnosis of electrical machines. 